\title{
Dramın Ardındaki Emek: Dizi Sektöründe Reyting Sistemi, Çalışma Koşulları ve Sendikalaşma Faaliyetleri
}

\author{
Yrd. Doç. Dr. Ergin BULUT
}

koç üniversitesi, medya ve görsel sanatlar bölümü ebulut@ku.edu.tr

\section{Abstract \\ Labor Behind the Drama: Rating System, Working Conditions and Unionization in Turkish Soap Opera Industry}

Through the concept and the experience of precarity, this article investigates the impact of rating system on the working conditions within Turkey's soap opera industry. Drawing on the findings from a fieldwork involving 26 participants, the article argues that precarity in this sector differs from that defined within contemporary studies on precarious media labor. Rather than a purely economic phenomenon, it is crucial to grasp soap opera precarity with its bodily, physical and legal dimensions. Additionally, the article suggests that workers in this sector are neither victims of their passion for the job, which leads to self-exploitation, nor do they fall prey to precarity. On the contrary, they resist precarious labor conditions. Campaigns targeting precarity and adverse working conditions in the industry are examined in this study. Ultimately, it is observed that organization attempts in this sector unfold differently than horizontal organizations resisting precarity. Unionization within this sector aims to convince the state to recognize performers, actors, provide professional definitions, and prevent workplace accidents, which at times do lead to deaths.

keywords: soap opera, labor, unionization, rating system, precarity 


\section{Résumé}

\section{Le travail derrière le drame : le système de mesure d'audience, les conditions de travail et les activités de syndicalisation dans l'industrie de série télévisée en Turquie}

En se focalisant sur le concept et l'expérience de précarité, cet article examine le système d'évaluation sur les conditions du travail dans l'industrie de série télévisée en Turquie. En se basant sur les résultats d'une étude de terrain menée auprès de 26 participants, l'article montre que la précarité dans ce secteur est différente de celle qui est définie par les études contemporaines sur le travail précaire dans les médias. II est important de comprendre la précarité des travailleurs des séries télévisées par ses dimensions matérielles, physiques et juridiques plutôt que de la considérer comme un phénomène purement économique. En outre, cet article souligne que les travailleurs dans ce secteur ne sont pas victimes de leur passion de travail qui les conduit vers l'autoexploitation, ils ne sont ni prie en proie par la précarité. Au contraire, ils résistent contre les conditions précaires du travail. Les campagnes qui visent la précarité et les mauvaises conditions du travail dans l'industrie sont examinées dans notre travail. Finalement, les tentatives d'organisation contre la précarité dans ce secteur sont également observées dans le cadre de l'ensemble des organisations horizontales qui luttent contre la précarité. L'objectif de la syndicalisation dans ce secteur est de convaincre l'Etat de reconnaitre les acteurs, de développer des définitions professionnelles, d'empêcher les accidents dans les lieux de travail causant parfois des décès.

mots-clés : l'industrie de série télévisée, le travail, la syndicalisation, le système de mesure d'audience, la précarité 
Öz

Bu makale, Türkiye'deki reyting sisteminin dizi sektöründeki çalışma koşullarına etkisini ve sendikalaşma faaliyetlerini, güvencesizlik kavramı ve deneyimiyle ilişkili olarak tartışmaktadır. 2014 Aralık'tan bu yana yirmi altı katıımcıyla yürütülen saha çalışmasına dayanan araştırma bulgularının ele alındığı makalede, sektördeki güvencesizliğin, eleştirel medya çalışmaları literatürü ve spesifik olarak da medya emeğine dair araştırmalarda ele alındığından farkı görünüm arz ettiği iddia edilmektedir. Dizi sektöründe güvencesizlik, sadece ekonomik ilişkiler ve istihdam boyutuyla ele alınmayacak kadar karmaşıktır. Bu sektörde güvencesizliğin, çalışanlar üzerindeki bedensel, fiziksel ve yasal boyutuyla kavranması şarttır. Buna ek olarak, dizi çalışanlarının güvencesizliğin, işlerine duydukları tutkunun ve bunun yol açtığı öz sömürünün esiri olmadığı ve direnme pratikleri geliştirdiği iddia edilmektedir. Dolayısıyla sektördeki olumsuz çalışma koşullarına ve güvencesizliğe karşı atılan adımlar ve geliştirilen kampanyalar, sendikalaşma faaliyetlerinden hareketle incelenmektedir. Sonuç olarak sektördeki örgütlenme faaliyetlerinin, güvencesizlik temelli yatay örgütlenme biçimlerinden farklı evrildiği, önceliğin devlet tarafından işçi olarak tanımlanmaya, meslek tanımlarının yapılmasına ve iş kazalarının önlenmesine verildiği görülmektedir.

anahtar kelimeler: Dizi sektörü, emek, sendikalaşma, reyting sistemi, güvencesizlik 


\section{Giriş}

Türkiye'de dizi sürelerine dair eleştiriler, 2010 yılında düzenlenen bir eylemde kullanılan "Yerli Dizi Yersiz Uzun" sloganıyla gündeme gelse de o günden bu yana dizi süreleri kısalmadığı gibi, 90 dakikadan 130 dakikaya, hatta 145 dakikaya uzadı. Günümüzde diziler, uzun süreleri veya setlerdeki olumsuz çalışma koşullarından ziyade, sektörün ekonomik boyutu ve ülke tanıtımına katkısı açısından toplumsal imgelemde yer buluyor. Zira Türkiye'de çekilen diziler Orta Doğu, Balkanlar ve hatta Latin Amerika'da kendisine alıcı ve izleyici bulmakta. Yetmiş beş ülkede 400 milyon izleyici tarafından izlenen Türk dizilerinden elde edilen yıllık gelir 150-200 milyon dolara ulaştığı gibi Türk yapımları, ABD'nin hemen arkasından ikinci sırada yer almakta ve dolayısıyla Türkiye'nin bölgesel aktör olma iddiaları çerçevesinde bir "yumuşak güç" olarak düşünülmektedir (Al Jazeera Türk 2014). Türk dizi ihracatının 2004'te bulunduğu 10 milyon dolar seviyesinden 200 milyon dolar seviyesine çıktığı ve Muhteşem Yüzyıl dizisinin 43 ülkede 200 milyondan fazla kişi tarafından izlendiği olguları beraber düşünüldügünde, sektördeki büyümenin küresel boyutları daha da netleşmektedir (Hürriyet Daily News 2014). Endüstrinin uluslararası boyutları öylesine büyümüştür ki dizi dünyasında önemli bir yer sahibi olan Lost'un yönetmeni Bobby Roth, Osmanlı polisiyesi Filinta'nın bazı sahnelerini çekmek için Türkiye'ye gelmiştir. Dolayısıyla bir "dizi turizmi"nden bahsetmek mümkündür (Monocle 2010; Alphan 2011). Dizilerin ekonomik ve kültürel boyutları bir arada ele alındığında, sektördeki çalışma koşulları ve işgücünün buna nasıl cevap verdiğinin incelenmesi önem arz etmektedir.

Türkiye'de son dönemde adından bahsettiren dizilerin boy gösterdiği ekranlara bakıldığında, yapımlarda ihtişam ve dramın oldukça önemli bir yer tuttuğunu görebiliriz. Ancak bu intişam, emek söz konusu olduğunda sadece birkaç yıldız oyuncu için geçerlidir. Dramın ise çok para kazandığı düşünülen oyuncuların geneli ve özellikle de set çalışanları için geçerli olduğunu tespit etmek mümkündür. Dizi yıldızlarının bazıları İstanbul'un mutenalaştıılan semtlerindeki yatıımlarıyla gündeme gelse de (Milliyet 2015), Engin Günaydın ve Nejat Iş̧ler gibi oyuncuların, setlerde iş kazalarına, beyin kanamalarına yol açan uzun çalışma saatleri nedeniyle artık dizilerde oynamayacaklarını açıklamış olmaları, dikkatleri tekrar az da olsa dizi setlerindeki çalışma koşullarına çekmiştir (Radikal 2015).

Ne var ki dizi sektöründeki kötü çalışma koşulları ve güvencesiz emeğin örgütlenmesi konusunda bilimsel araştırmalar yok denecek kadar azdır. Dizilerle ilgili araştırmalar, endüstriye dair betimleyici çalışmalar (Tanrı̈̈ver 2010), dizilerdeki temsiller (Çaylı 2012; Ertan 2013), ürün yerleştirme (TüzünAteşalp ve Taşdemir 2014) ve değişen jeopolitik koşullar bağlamında "yeniOsmanlı cazibesi" (Kraidy ve Al-Ghazzi 2013; Tüzün ve Şen 2014) kavramının tartışılmasıyla sınırlı kalmıştır. Fırat Konuşlu'nun (2014) dizi sektöründeki çalışma koşullarına dair değerli çalışması, bilgi işçisi, gayrı maddi emek gibi kavramlara sınıf temelli teorik bir eleştiri getirmektedir. Mevcut çalışma için önemli bulgular 
sunsa da Konuşlu'nun (2012: iv) çizgi üzerindeki1 (above the line) sektör çalışanlarının "güvencesiz çalışma koşullarından fazla etkilenmedikleri" şeklindeki argümanının daha yakından incelenmesi gerekmektedir. Çünkü yazının ilerleyen kısımlarında da tartışılacağı gibi yeni reyting sistemi, güvencesizliği derinleştirdiği gibi bir anlamda da "demokratikleştirerek" çizgi üzerindeki çalışanları da -oyuncu, senarist, yönetmen- daha güvencesiz bir ortamda çalışmak durumunda bırakmıştır. Dolayısıyla Konuşlu'nun (2012) güvencesizliğin tabakalı ve eşitsiz yapısına dair düşüncesi önemli olmakla beraber, yeni reyting sisteminin, uzayan dizi süreleriyle beraber dizi sektöründe çalışanların bedenlerine etkisi ve sektördeki örgütlenme çabalarıyla ilişkisi birlikte ele alınmalıdır. Konuşlu'nun da vurguladığı gibi senarist ve yönetmen gibi çizgi üzeri çalışanların çalışma koşulları daha elverişli olabilir. Ancak bu durum, onların da oldukça tahmin edilemez nitelikli yeni reyting sistemi nedeniyle uzun saatler çalıştığı ve istihdamlarının kesintiye uğradığı gerçeğini ortadan kaldırmaz. Yeni reyting sisteminde herhangi bir dizinin dört beş bölüm çekildikten sonra yayından kalkmama garantisi yoktur. Bu da çizgi üzeri set çalışanlarının hayatlarının da aslında güvencesiz olduğu ve bir senaristin de belirttiği gibi "canavarca" bir ortamda sürdürüldüğü anlamına gelmektedir. Dolayısıyla güvencesizlik, dizi çalışanları tarafından farklı derecelerde deneyimlense de dizide emek sarf eden hemen herkesin içinde olduğu ortamı tanımlamaktadır. Yani güvencesizlik açısından farklılıklar olduğu kadar ortaklıklar da söz konusudur. Çizgi üstü çalışanların sendikası (Oyuncular Sendikası) ve çizgi altı çalışanların sendikasının (Sinema TV Sendikası) birlikte çalışmalar yapıyor olması da güvencesizlik anlamında ortaklıklara işaret etmektedir.

Bu makale, ana akım medyada sektörle ilgili haberler, endüstri raporları, medya emeğine dair eleştirel literatür ve bir yıldan fazla süren bir saha çalışması kapsamında yapılan set ziyaretlerindeki gözlemler ve yarı yapılandırılmış görüşmeler üzerinden; yeni reyting sisteminin, dizi emeğinin halihazırdaki olumsuz koşullarını daha da kötüleştirdiğini ve güvencesizliği artırdığını öne sürmektedir. Devletin reyting sistemini yeniden düzenlemek adına yaptığı müdahale, çalışma koşullarındaki kötüleşmeyi anlamak açısından önem arz etmektedir. Söz konusu müdahale, güvencesizliği derinleştirip çalışma saatlerini artırmış, buna paralel olarak da dizi sektöründeki çalışanların boş zamanlarının neredeyse yok olmasına yol açarken, bedensel bir külfet getirmiş ve çalışanların yaratıcılıklarını sınırlandırmıştır. En önemlisi de iş kazalarına ve ölümlere yol açmıştır. Dolayısıyla yeni reyting sistemi, güvencesizliğin sadece ekonomik değil, bedensel, fiziksel ve yasal olarak kavranması açısından kilit konumdadır. Medya emeğiyle ilgili olarak çalışılan ve tartışılan güvencesizlik kavramı ve deneyimi, Türkiye'deki yapısı itibarıyla, Kuzey Amerika ve Avrupa bağlamından farklıdır. Bir yandan güvencesizlik, istihdam koşullarıyla ve ekonomik güvenceyle ilintilidir. Ancak ölümler ve ciddi yaralanmaların meydana gelmiş olması, Türkiye bağlamındaki güvencesizliğin bedensel ve fiziksel olduğunu ve dolayısıyla sadece ekonomik

1 Çizgi üstü ile, üretilen eserde yaratıcı katkısı fazla olan işçiler kast edilmektedir. Dizi sektörü söz konusu olduğunda bu gruba senarist, yönetmen, görüntü yönetmeni girebilmektedir. 
bir mesele olarak kavranamayacağını göstermektedir. Buna ek olarak makalede, sektördeki güvencesizliğe karşı verilen mücadelenin, yaratıcı endüstrilerde küresel olarak görülen yatay ve network temelli örgütlenmelerden farklı olduğu iddia edilmektedir. Bu farklılı̆ın temelinde de hem Türkiye'de devlet-dizi sektörü-oyuncu arasındaki çarpık ve enformel ilişkiler, hem de sendika üyelerinin kendilerini yaratıcı olmalarının yanı sıra aslında işçi olarak tanımlamaktaki ısrarı yatmaktadır. Araştırma kapsamında görüşülen Oyuncular Sendikası çalışanlarının da vurguladığı gibi dizi sektöründeki güvencesizlik, aynı zamanda yasal bir güvencesizliğe işaret etmektedir. Zira set çalışanları açısından meslek tanımları net bir şekilde yapılmadığı için, örgütlenme mücadelesi ekonomik hedeflerin yanı sıra, çalışanların devlet tarafından açık bir şekilde "işçi" olarak tanımlanmasını da hedeflemektedir. Dolayısıyla sektörün dinamiklerini, iş gücünün deneyimi ve örgütlenme kampanyaları üzerinden incelemek önem arz etmektedir.

Araştırmanın temelini oluşturan saha çalışması, 2014 Aralık'ta başlamıştır ve hâlâ devam etmektedir. Saha kapsamında 26 kişiyle görüşme gerçekleştirilmiştir. Görüşmeler senarist, görüntü yönetmeni, oyuncu, uygulayıcı yapımcı, ışık şefi, yapım koordinatörü, şoför, çaycı, makyaj, reji ekibi gibi dizi üretiminin farklı alanlarında yer alan kişileri ve sendikal faaliyet gösteren bireyleri kapsamaktadır. Görüşmelerin büyük bir kısmı setlerde ve sendika binasında gerçekleştirilmiştir. Katıımcılar için kullanılan isimler, kişilerin gerçek ismi değildir. Setlerin dinamik ve değişken yapısına ek olarak çekim planları ve mekânlarının sıkça değişebilmesi, görüşmelerin yapılmasındaki en önemli engellerden birisini teşkil etmiştir.

Saha çalışması kapsamında görüşme yapılan hemen her kişi, yeni reyting sisteminin setteki zaman ekonomisini hızlandırdığını ve yapım şirketlerinin de bu yeni ekonomiye her hafta 140 dakikalık bölümlerle cevap vermek durumunda kaldığını dile getirmiştir. Yapım şirketlerinin iş gününü uzatmak ve mutlak artı değer sömürüsünü artırmaya dönük bu stratejisi, adeta iki tarafı keskin bir kılıç işlevi görmektedir. Bir taraftan çalışanlar, uzun çalışma saatlerine işin sembolik değeri ve dışarıda yaptıkları işi yapmaya gönüllü çok sayıda kişi; yani büyük bir yedek iş gücü ordusu olması nedeniyle katlanmaktadır. Bir ışık şefinin de belirttiği gibi yedek iş gücü ordusu öylesine önemli bir faktördür ki "birisinin sizin işinizi yapması, yeni alınacak kişinin alım yapan sete mesafe açısından İstanbul'da nerede olduğuna bağlıdır". Ancak bir taraftan da söz konusu mutlak artı değer sömürüsü artık "insan bedeninin fiziksel ve psikolojik sınırlarına" ulaşmış (Fuchs 2013: 11) ve iş kazalarıyla ölümlere yol açarak kolektif eylemi de beraberinde getirmiştir. Sektördeki olumsuz çalışma koşullarının hafifletilip hafifletilmeyeceği ise hem set çalışanlarının hem de oyuncuların sendikalar aracıı̆̆ıyla yürüteceği mücadelenin seyrine ve devletin oyuncuların işçi olarak tanınma çağrılarına nasıl cevap vereceğine bağlı olacaktır.

Medya ve iletişim çalışmalarında emeğin görünmezliği, son dönemde yapılan çalışmalarla bir nebze de olsa azalmıştır. Video oyun endüstrisi (DyerWitheford ve de Peuter 2009; Kerr, 2006; Binark ve Bayraktutan-Sütçü, 2008), 
sosyal medya ve dijital emek (Terranova 2000; Fuchs 2014; Scholz 2012) ve dijital gazetecilik (Cohen 2015) gibi alanlarda çalışmalar, dijital teknolojiler ve emek arasındaki ilişkiye dair eleştirel perspektifler sunmuştur. Özel olarak televizyon ve film alanına, üretim çalışmaları perspektifinden bakılmıştır (Mayer vd. 2009; Ursell 2000; Blair 2001; Hesmondhalgh ve Baker 2011). Ancak Michael Curtin'in (2008) belirttiği gibi gelişmekte olan medya üretim merkezlerini incelemek de önem arz etmektedir. Daha da önemlisi, medya çalışanları ve güvencesizlik konusundaki değerli çalışmalar genellikle iki anlatı üretmiş ve kültür emekçilerini "neoliberalizmin model özneleri veya güvencesizliğin mağduru" şeklinde kodlamıştır (de Peuter ve Cohen 2015: 305). Greig de Peuter ve Nicole Cohen'in de belirttiği gibi "kültür emekçilerini, çalışma koşullarının iyileştirilmesi konusunda da çalışmalar yapan aktivistler ve değişimin özneleri olarak görmek, iletişim ve kültürel emek çalışmaları alanındaki araştırmaların, örgütlenme ve güvencesizliğe direnme meselesini daha derinden ele almasını gerektirir" (de Peuter ve Cohen 2015: 305).

Bu anlamda Türkiye'deki dizi sektöründe sendikalaşma konusunda başı çeken Oyuncular Sendikası'nın çalışmalarına bakıldığında çeşitli unsurlar ortaya çıkmaktadır. Sendika öncelikle farkındalık kampanyaları yürüterek kamuoyunu, dizi sektöründeki çalışma koşullarıyla ilgili bilgilendirmektedir. Buna ek olarak, devletin ilgili birimleriyle görüşmeler gerçekleştirerek hem çalışma koşullarının iyileştirilmesi için çabalamakta hem de öncelikle oyuncuların işçi olarak tanımlanmasını sağlamayı amaçlamaktadır. Böylelikle oyuncuların serbest çalışan değil, işçi olarak tanınması ve sözleşmelerinin de buna uygun olarak yapılması hedeflenmektedir. Bir sendika çalışanının da belirttiği gibi tek sorun aslında uzun dizi süreleri değil, oyuncuların iş yasası üzerinden işçi olarak tanımlanmaması ve setlerde de meslek tanımlarının net yapılmamış olmasıdır².

Dolayısıyla bu noktalar mevcut medya emeği ve güvencesizlik literatürüyle bir arada düşünüldüğünde, Türkiye'de dizi sektörüyle sektördeki güvencesizlik ve örgütlenme koşullarının, Kuzey Amerika veya Avrupa ile farklııklar arz ettiği görülmektedir. Çünkü Türkiye'de dizi çalışanları kendilerini yaratıcı sınıf olarak görmektense (Florida 2005), öncelikle devlete kendilerini işçi olarak tanıtmaya çalışmaktadır. Dolayısıyla iş yerinde ve emek sürecinde özerklik gibi alanlardan faydalanıp yaptıkları işin sembolik değerine kapılmaktansa, uzun çalışma saatlerinin yol açtığı sömürü koşullarına sınıfsal pozisyonlarını yasal alanda tanımlamaya çalışarak direnmeye çalışmaktadır.

Makalenin geri kalan kısmında öncelikle sektörün yapısal dinamikleri betimlenecek, ardından reyting sistemi ve bunun çalışma koşullarına etkisi,

2 Oyuncuların işçi olarak tanımlanması, sigorta primlerinin ödenmesi yükümlülüğünü oyunculardan alıp yapım şirketlerine aktaracaktır. Buna ek olarak oyuncular serbest meslek erbabı değil de işçi olarak sınıflandırılacağı için, çalışma saatlerinin düzenlenmesi de mümkün olacaktır. 
sektör çalışanlarının deneyimlerinden hareketle tartışılacaktır. Daha sonra, Oyuncular Sendikası'nın düzenlediği iki kampanyadan hareketle, sektördeki yasal ve bedensel güvencesizliklerin giderilmesi için yürütülen mücadele ve taktiklerden bahsedilecektir. Sonuç kısmında da altı çizilen güvencesizlik ve buna karşı verilen mücadelenin özgünlüğü, yaratıcı endüstriler tartışmaları bağlamında ele alınacaktır.

\section{Sektörün Yapısal Dinamikleri ve Aktörler: Kanallar, Yapım Şirketleri ve Çalışanlar ${ }^{3}$}

Dizi sektörünün yapısı oldukça parçalı bir görünüm arz etmektedir. 20102014 yılları arasında 85 şirketin faal olduğu sektörde, bu 85 şirketten 21 'inin beş veya daha fazla, 22 şirketin 2 ila 4 arası, geriye kalan 41 yapım şirketinin de sadece bir dizi çektiği belirlenmiştir. Sektörün büyüklüğü göz önüne alındığında, "sektöre girişin kolay ancak başarı elde etmenin zor" olduğu (Randle 2011:148) dikkat çeker. Uygulayıcı yapımcı Tilbe'nin de belirttiği gibi, "Bu sektörde CV sistemi yok. Daha çok bir ekip olmakla, işinizi ne kadar iyi yaptığınızla ve isminizi duyurmakla alakalı. Eğer iyi bir ekibin parçasıysanız, o zaman beraber ilerlersiniz. Freelance iseniz ve işinizi iyi yapıyorsanız, yine işe alınırsınız". Yani sektörde istihdam edilmenin yolu, enformel bağlantılardan ve iş üzerinden isim yapmaktan geçmektedir.

Endüstrideki ilişkiler hiyerarşiye dayanmaktadır. Televizyon kanalları, mali riski yapımcı şirketlere aktarmaktadır. Kanallar, kiminle çalışacakları konusunda seçici davrandığı için, isim yapmış yapım şirketlerinin daha avantajı olduğu söylenebilir. Yapım şirketleriyle anlaşmalar on üç bölümlüğüne yapılmakla birlikte televizyon kanallarının yaptıkları anlaşmayı her an iptal etme hakkı bulunmaktadır. Ne var ki, düşük reyting oranları, yapım şirketleriyle yapılmış kontratların otomatik olarak sona ereceği anlamına da gelmemektedir. Örneğin, görüşme yapılan uygulayıcı yapımcı Ahmet'in görev aldığı dizi, düşük reytinglere rağmen hâlâ yayındaydı. Zira TV kanalı bu dizi üzerinden yurt dışı satış anlaşmaları yapmış ve buradan gelir elde etmekteydi. Ancak yine de dizilerin iptal edilme oranları öyle yüksektir ki her sezon 50-70 arasında yeni dizi yayına girmekte, bunların yarısından fazlası yayından kaldırımaktadır. 30 Haziran 2014 tarihi itibarıyla yayındaki 39 diziden 26'sının (\% 67) ilk sezonunda olması, sektördeki sirkülasyonu anlatması açısından önemlidir.

200.000-700.000 dolar arasında değişen dizi çekim maliyetlerinin en büyük kalemini oyuncuların maaşları oluşturmaktadır. Çekim için Türkiye'de özel dizi platolarının olmaması, üretim maliyetlerini artıran önemli bir etken olarak göze çarpar. Platolar olmadığı için yapım şirketleri farklı mekân arayışlarına girmekte, bu da hem zaman hem ulaşım masrafı anlamına geldiği gibi iş gücünün de

3 Makalenin bu kısmında ve bir sonraki kısımda, Deloitte'ın kapsamlı sektör raporundan faydalanılmıştır. 
daha fazla kullanılmasına yol açmaktadır4 . Buna ek olarak diziler birkaç bölüm çekildikten sonra yayından kaldırılabilmekte ve bu da gerek kostüm gerek dekor masraflarını artırmaktadır.

Bu hiyerarşik yapı içerisinde yapım şirketleri, kurdukları “bölüm başı ödeme sistemi" sayesinde esnek üretim süreçlerini devreye sokarak üstlendikleri riski azaltmakta, böylece yapım şirketlerinin maddi kaybı azalırken dizi çalışanları güvencesiz konuma itilmektedir. Her ne kadar sektörde yıldız denilebilecek birkaç isim ön ödeme gibi koşulların yer aldığı sözleşmeler yapabilse de set çalışanları bu imkândan yoksun olduğu gibi kendilerine ödenen ücretler çok düşük durumdadır. Bölüm başına 2015 yılı itibarıyla 200-300 TL alındığı, görüşmeler sırasında araştırmacıya aktarılmıştır. Dolayısıyla bölüm başına ödeme yapılması, set çalışanlarını zor duruma sokmaktadır. Bu sistemde bir set çalışanı, dizinin bir bölümünü çekmek için dört hafta çalışsa bile, alacağı ücret bölüm başına anlaşılan ücret üzerinden gerçekleşmektedir. Yapım koordinatörü Nazım da bu durumdan şikâyetini şöyle anlatır:

"Biz bu projeye beş ay önce başladık. Haftada bir bölüm çektik desen, yirmi bölüm eder. Diyelim ki ilk bölümü çekmen iki hafta sürdü, o zaman on dokuz bölüm eder. Ama biz daha on üçüncü bölümü bitirebildik. Yani benim altı haftalık kaybım var".

Ağır çalışma koşulları ve set hiyerarşisine rağmen sektörde rızanın üretimi, diğer yaratıcı endüstrilerde olduğu gibi medya emeğine dair şatafatı söylem veya Miya Tokumitsu'nun (2014) Steve Jobs'a referansla söylediği "sevdiğin işi yap" mantrası üzerinden gerçekleşir:

“Bu çok parlak bir dünya, bunu kabul etmek lazım. Gerçi 50. bölümü çekerken kendinizi sosis fabrikasında çalışıyor gibi ya da vergi dairesinde memur gibi hissediyorsunuz. Ama sonuç olarak büyülü bir dünyası var. Bir ürün çıkıyor ortaya ve onun bir yerlerinde sizin isminiz yazıyor. Bütün insanlar da bunu görüyor. Bu iş egosu biraz kuvvetli insanların yapacağı bir iş. Bunu kabul etmek lazım." (Tilbe, uygulayıcı yapımcı)

"Ya adamın sevdası vardır bu işe. Sevda için de bu ıstırap çekilir mi, diyeceksin ama en üste gelmeyi hedefliyor. Yönetmen olduğunda şöhret olacak. Ciddi paralar kazanacak. Bu hedefinden dolayı kendini bile bile ezdiriyor. Hepimiz birlik olalım, ezdirmeyelim ve sen asistanken de hakkını al. Ama o sadece hedefine kitlenmiş. 'Günü gelecek ve ben de başkasını ezeceğim' diyor." (Ahmet, oyuncu)

"Dünyada para olmasaydı ben yine dizi çekmek isterdim. Para için değil, sevdiğim için yapıyorum bu işi. Benim aşkım bu, başka bir şey yapamam zaten. ilerde iyi iş çıkardığın zaman zaten iyi para da kazanmaya başlıyorsun. Birbirlerini bütünlüyor bunlar." (Doruk, DIT operatörü).

4 Saha çalışmasındaki görüşmelerde de senaristlerin farklı mekân, özellikle de dış-gece tercihlerinin iş gücü açısından yarattığı problemlere sıklıkla dikkat çekilmiştir. 
Bu araştırma kapsamında görüşülen bir dizi setinin çaycısı da eğitimi olmasa da ileride yapım ekibine katılmayı istiyordu. Bu anlamda, sektörle ilişkilendirilen ün ve tanınmanın cazibesi nedeniyle "alttakiler büyülenmiş durumda", yani "vampir ayartıcı" (Ursell 2000: 818-821). Sektörde, "ücretli istihdam, ücrete dayalı olmayan değişimler ve gelecekte gerçekleşmesi beklenen sembolik mübadeleler"e dayalı bir karma ekonomi söz konusu ve bu ekonomi, sektör çalışanlarının sömürü koşullarına katlanabilmesini sağlamakta. Saha çalışması sırasında işi bırakan Ebru ise farklı düşünüyor; ona göre bu sektör "parayı seven tembel insanların olduğu" bir yer. Eğitim-istihdam ilişkisine dikkat çeken Doruk ise "üniversite okuma gibi bir kriter yok" diyor, yani istihdam "ün ve tanınırlık" sayesinde gerçekleşiyor (Ursell 2010: 811).

Sonuç olarak bulgular, sektörün oldukça esnek ve hiyerarşik bir yapıya sahip olduğunu göstermektedir. Hiyerarşi zincirinde TV kanalları, yapım şirketlerinin üzerinde bulunmakta ve yapım şirketleri de iş gücünü sömürerek maliyeti azaltmaya çalışmaktadır. İş gücünün içinde bulunduğu sosyallik ise akışkanlığın, enformelliğin, iş ve oyunun iç içe geçmesinin ve bireyselleşmenin karakterize ettiği bir sosyallik olarak tanımlanabilir (Wittel 2001). Ne var ki kanallar, yapımcı şirketler ve işçiler dışında bir aktör daha bulunmaktadır: Devlet.

\section{“Dünyanın En Renkli Ekranı"nın Ölçülmesi: Reyting Kaosu}

Türkiye'de günde ortalama yaklaşık dört saat televizyon izlendiği ve bunun OECD ortalamasının üstünde olduğu düşünüldüğünde, reklam yatıımlarının yarısının hâlâ televizyona yapılması şaşırtıcı olmayacaktır. Her ne kadar 1980'lerden bu yana liberalizasyon yaşansa da bir mecra olarak televizyonun regülasyonunda devlet hâlâ önemli bir söz sahibidir ve bunun en görünür alanlarından birisi reyting sistemidir.

Sistemin düzenlenmesi, 1990-2012 arasında AGB Nielsen şirketi tarafından yapılmaktaydı. TRT, 2009-2012 arasında sisteme katılmayı reddetti. Reyting sisteminin ekonomi politik dönüşümü Aralık 2011'de gerçekleşti. Zira sistemden sorumlu TiAK (Televizyon İzleme Araştırmaları A.Ş.), AGB Nielsen'le anlaşmasını feshederek TNS ile yeni bir anlaşma yaptı. TNS şirketinin ölçümler için gerekli altyapıyı bitirdiği 2012 yıına kadar reyting ölçümü yapılmadı. Ne var ki AGB Nielsen ve TNS arasında ölçüm metodu ve örneklem boyutuna dair farklar nedeniyle reyting sistemi konusundaki tartışmalar, TNS ölçümleri yapmaya başladıktan sonra da bitmedi. Zira AGB Nielsen'le olan anlaşmanın, şirketin ölçümlere katılan 1100 haneye dair bilgiyi sızdırdığı iddiasıyla iptal edildiği belirtilmekteydi. Ancak AGB Nielsen ile olan anlaşmanın siyasi nedenlerle iptal edildiği ve kurulacak yeni sistemle 3.8 milyar dolarlık reklam pastasının yeniden dağıtılarak televizyon dünyasının ideolojik olarak dönüştürülmesinin hedeflendiği iddia edilmekteydi. 
Peki reytinglerin ölçümü nasıl değişti? İhaleyi kazanan TNS, ölçüm yaptığı denek grubunun içeriğini genişletti ve artık AB grubuna dâhil olmak için hanedeki eğitim durumu (üniversite mezunu olma koşulu) yerine, belli bir gelir seviyesi şartı getirildi. Dolayısıyla AB grubunu kültürel değil ekonomik sermaye belirler hâle geldi. Yeni reyting sistemiyle beraber ölçüm cihazlarının yerleştirildiği bölgeler genişledi ve nüfusu iki binden az yerlerde de reyting ölçümü yapılır hâle geldi. Yani kültürel beğeninin ölçümü için kullanılan sistemin anlaşılamaz olması, yapım şirketlerini de zor durumda bırakmakta. Dolayısıyla eski haliyle de tartışıır durumdaki reyting ölçüm sistemi, hepten karmaşıklaştı ki Armağan Çağlayan bu durumun devam etmesi halinde " 5 sene sonra bu televizyon dünyasında bana iş düşmez" diyor ve bu durumu da Küçük Gelin gibi dizilerin hitap ettiği dünyaları tanımamasına bağlıyor.

Sonuç olarak reyting sistemine yönelik müdahale ve deneklere dair karmaşa, dizilerin alışılagelmiş dönemsel yayın düzenini radikal anlamda dönüştürdü. Uygulayıcı yapımcı Tülay'ın da söylediği gibi, “Eskiden Eylül ve Ocak dizileri vardı. Şimdi diziler peş peşe iptal ediliyor. Sezon ortasında oyuncularımız ve teknik ekip şimdi işsiz". Sektörde belirsizlik ve kaos o kadar yoğun hissedilmekte ki, araştırma sırasında set çalışanlarıyla buluşmak için ortak zaman belirlemek çoğu zaman sorun oldu. Örneğin, ışık şefi Ali o dönem çalışmamasına rağmen -2015 Aralık- yeni bir diziye başlayıp başlamayacağını kestiremiyordu ve ertesi gün set verilebilirdi. Dolayısıyla ancak bu durum netleştikten sonra bir araya gelinebildi.

Söz konusu kaosa ve dizilerinin art arda yayından kaldırılmasına rağmen TV izleyicisinin dizilere düşkünlüğünün azalmadığı gibi arttığı görülmekte. En çok izlenen altı kanalda diziler ve tekrarları \% 60-65 gibi yüksek oranlar alırken dizi tekrarları bile, prime time'da en çok izlenen beş program arasına girebilmektedir. İzleyicinin dizilere ilgisine karşılık verebilmek için, bir uygulayıcı yapımcının da vurguladığı gibi, “TV kanalları yapımcılardan dizileri daha uzun çekmelerini talep etti ve süreler 90 dakikadan 130 dakikaya çıkarıldı". Önceki haftanın özetleriyle birlikte bu süreler 150-180 dakikaya kadar ulaşabilmekte. Örneğin Paramparça dizisi, son iki yıldır reytinglerde ön sıralarda yer alan Karadayı adlı diziyi geçince, Karadayı́nın süresi uzatıldı ve Paramparça da bir sonraki hafta buna aynı şekilde cevap verdi. Bu rekabet koşullarında TV kanalları ve yapım şirketleri daha yenilikçi üretim teknik ve stratejilerini benimsemektense yıldızlara ve tekrara dayanan senaryolarla çalışmayı tercih ediyor. Gillian Ursell'in (2000: 819) İngiltere bağlamı için belirttiği gibi "televizyon emek piyasasının tepesini alkış, ödül ve tanınma belirliyor". Ne var ki yıldızlarla çalışmak ucuz değil. Üstelik RTÜK, dizi sırasındaki reklam sürelerini de sınırlandırdığı için kanalların çıkış yolu, dizi sürelerini artırmak oldu. Bu da dizi çalışanları için büyük sıkıntı kaynağı yaratıyor.

Sektörün yapısal dinamikleri ve reyting sistemindeki dönüşümün ardından, makalenin takip eden kısımlarında, reyting sisteminin çalışanların bedenine olan etkisine ve sektör çalışanlarının bu koşullara nasıl tepki verdiğine odaklanılacaktır. 


\title{
Uzun Çalışma Saatleri: “Dizi değil her hafta film çekiyoruz"
}

2010 yılında dizi sektöründe çalışanlar, "yerli dizi yersiz uzun" sloganının ön plana çıktığı bir eylem düzenleyerek dizi sürelerinin 90 dakikadan 45 dakikaya azaltılması taleplerini dile getirdiler. Söz konusu eylem, yetkililere sektördeki çalışma koşullarını incelemeleri konusunda çağrıda bulunsa da atılan adımların yeterli olmadığı görülmektedir. Çünkü bir uygulayıcı yapımcının da söylediği gibi kanallar "reklam pastasının daha fazlasını" istemektedir. TV kanallarının bu tutumu, çalışma saatlerinin uzamasına ve sektör çalışanlarının boş zamanlarının neredeyse yok olmasına yol açmaktadır. Set çalışanı Mehmet:

\begin{abstract}
“Bizim prodüksiyondan bir arkadaşımız izin gününde (Cumartesi) 5 yıllık kız arkadaşını alıp güzel bir mekâna gitmiş. Tam yüzügü çıkarıp evlenme teklif edecekken telefon çalıyor. Bilmem ne DVD'sinin oradan oraya götürülmesi gerekiyor. Gece saat bilmem kaç. Biz de Kurtköy'deyiz, yetişme şansımız yok. Doğal olarak çocuk isyanda. Çünkü izinli."
\end{abstract}

Doruk'a da boş zamanında ne yaptığı sorulduğunda "Eve yatmaya gidiyorsunuz sadece. İzin günü komple uyumakla geçiyor. Sosyal aktivite yapabilirsen ne mutlu" yanıtını veriyor. Çizgi üstü çalışan konumundaki Tülay'ın durumu da farksı:

\begin{abstract}
"Ben de istiyorum ki daha makul sürelerde çalışılsın. Ben mesela 2 aydır diyebilirim ki hiç repo (izin) yapmadım. 2 ekip var. Bu aslında kişisel tercih. Kalkıp gitmeyebilirim ama gitmeyi tercih ediyorum. O kadar büyük bir şeyi kontrolsüz bırakmamak gerekiyor. Çünkü bir sorumluluk taşıyorsunuz. Hayatın kaçtığını hissediyorsunuz bu işin içindeyken. Ben eşimle sinemaya gitmedim, bir yere yemeğe gitmedim. Evet, ben tatminkâr bir para kazanıyorum ama onu keyifle yeme şansım yok."
\end{abstract}

Her ne kadar sektörde çalışma saatlerine yönelik tepki, koşulların düzeltilmesi umudunun önüne geçiyor gibi görünse de oyuncular ve set çalışanlarının örgütleniyor olması, güvencesizliğin bir kader olmadığına, oyuncuların ve set çalışanlarının da mağduriyetlerine boyun eğmediğine işaret etmektedir.

\section{Dizi Sektöründe Sendikalaşma: “Bizler işçiyiz”}

Gamze Yücesan-Özdemir (2014), çağrı merkezleri hakkındaki kapsamlı çalışmasında güvencesizlik kavramının iş güvencesizliği, istihdam güvencesizliği, sosyal güvencesizlik, gelir güvencesizliği, sendikal güvencesizlik, demokratik güvencesizlik ve irade güvencesizliği gibi farklı deneyim biçimlerinden bahseder. Türkiye'de dizi sektöründeki sendikalaşma faaliyetleri söz konusu olduğunda, bir tür irade güvencesizliği olduğundan bahsetmek mümkündür. Saha çalışması kapsamında görüşülen hemen herkesin, kolektif eyleme inançsızlığını dile getirmesi dikkat çekmektedir. 
"90 dakikaya çok derken 120 dakika çekmeye başladık. En azından günlük çalışma saatini standart hale getirmek gerekiyor. Bu kadar düzensiz büyüyen bir piyasada ne kadar umutlu olunabilir, bilmiyorum." (Görüntü yönetmeni)

"Boş boş konuşuluyor. Mangalda kül bırakılmıyor, 'durduralım dizleri, birlik olalım' deniliyor. 'Hadi' deyince arkana bir bakıyorsun kimse yok." (Oyuncu)

Yapım koordinatörü Nazım'ın “Eylem yaptığımızda süreler 90 dakikaydı. Şimdi 140 dakika çekiyoruz" şeklindeki alaycı söylemi, Mark Banks'in (2010) "statü pozu olarak otonomi" tanımıyla bir arada düşünüldügünde sinik bir eylemsizliğe yol açmakta:

“Onlar (başrol oyuncular) kısa sürede sıyrılmış ve yukarıdaki yerini garantilemiş adamlar. Onlar için geçerli değil bu. Dizi 5 bölüm sonra da bitse umurlarında değil. 70 bin liradan 350 bin lira yapar. 5 bölüm sonra patlayan bir dizi bizim için bütün sezonun aç geçmesiyken, onun için bir daire parası. O yüzden alt tabakayla birlik olmuyorlar. Tepedeki bu isimler birlik olup seti durdursa bak adalet nasıl geliyor piyasaya. Hiçbir zaman birlik olamıyoruz. Sendika var ama hiçbir halta yaramıyor." (Oyuncu)

Sektördeki rekabet ve örgütlenme isteksizliğine ek olarak, iş kaybetme kaygısı da önemli bir faktördür. Zira sektör küçük olduğundan iş bulmak için, yapımcılarla arayı iyi tutmak önem arz etmektedir. Ancak bu kasvetli havaya karşın örgütlenme çalışmaları sürmektedir. Bir yandan enformel iletişim grupları, sektör çalışanları arasındaki dayanışmanın önemli bileşenlerinden birisi olarak da göze çarpmaktadır:

\footnotetext{
“Bunu ilk başlatan görüntü gruplarıydı. Onlar başarılı da oldular. Çalışma saatleri ve alınan ücretleri ana konulardı. Ben de kurdum yapımcılar Whatsapp grubu bir hafta önce. Bir haftalık bir şey, herkes yazıyor memnun şu anda ihtiyaçları olsun haberler olsun. İşte birinci asistan lazım, mekâncı lazım, başladı ufak ufak. Buradan bir yerlere gidilir diye umut ediyorum." (Idari yapımcı)
}

Sendikalaşma açısından ası önemli gelişme, 2011 yılında "sahne, perde, ekran ve mikrofon alanında performans gösteren" oyuncuların bir araya geldiği Oyuncular Sendikası'nın kurulması olmuştur. Çizgi üstü kültür emekçilerini barındıran Oyuncular Sendikası'nın faaliyetleri, sadece dizi oyuncularıyla sınırlı olmasa da özellikle dizi sektöründe çalışan oyuncuların çalışma koşulları, dizi oyuncularının medyadaki görünürlüğü ve sektörün ekonomik hacmi, Oyuncular Sendikası'nın faaliyetlerini özellikle dizi sektörüyle ilişkili olarak ön plana çıkarmaktadır.

Internet sitesindeki listeye göre 1034 üyesi bulunan Oyuncular Sendikası'nın varlık sebebi sanılı̆̆ı gibi sürelerin kısaltılması olarak düşünülmemelidir. Sendika çalışanlarıyla yapılan görüşmelerde bu durumdan duyulan rahatsızlık dile getirilmekle beraber, sendikanın varlık sebebi, oyuncuların serbest meslek erbabı yerine işçi olarak tanımlanması ve sözleşmelerinin de bu minvalde yapılmasını sağlamak olarak görülmelidir. İstanbul Üniversitesi'nde bir konuşma 
yapan sendikanın hukukçusu Sera Kadıgil de 1960'lardan bu yana oyuncuların işçi yerine serbest meslek erbabı olarak değerlendirilmesinin hukuki bir yanlışlık olduğunu ve yapım şirketlerinin bu boşluktan yararlanarak oyuncuların sosyal sigorta primlerini ödemeden bugüne geldiğini belirtmektedir. Kadıgil, oyuncuların işçi olarak tanımlanmaması için mevcut iş yasasında herhangi bir boşluk olmadığını dile getirerek, işçi olarak tanımlanmanın önemine dikkat çekmiştir. Kadıgil'in de belirttiği gibi işçi olarak tanımlanmak, oyuncuların bağımlı çalışan kategorisine göre sınıflandııımasını sağlayacaktır. Mevcut koşullarda işçi olarak tanımlanmamak ise, oyuncuların uzun saatler çalışmasının önünü açmaktadır. Zira mevcut durumda oyuncular işçi (bağımlı çalışan) değil serbest meslek sahibi insanlar olarak değerlendirilmektedir.

$\mathrm{Bu}$ bağlamda kurulduğu günden bu yana Oyuncular Sendikası'nın yürüttüğü dört kampanya bulunmaktadır: 4A kampanyası, çocuk oyuncu kampanyası, işçi sağlığı ve iş güvenliği kampanyası ve meslek tanımı çalışması. Sektörün kaotik yapısı düşünülecek olursa, kampanyaların her birinin ne kadar önemli olduğu anlaşılacaktır. Ancak makalede, uzun çalışma saatleriyle ve reyting sistemiyle doğrudan alakası olması bakımından 4A Kampanyası ile İşçi Sağlığı ve Iş Güvenliği Kampanyası'na odaklanılacaktır. Çünkü bu kampanyalar, oyuncuların yasal statülerini tanımlamak ve iş yerindeki tehlike ve risklerin yanı sıra esnek ve uzun çalışmanın beraberinde getirdiği karmaşıklıkları ortaya çıkarmak açısından merkezi konumdadır.

\section{A Kampanyası: "Biz maça 2-0 geriden başlıyoruz"}

Adını Sosyal Güvenlik ve Genel Sağlık Sigortası Kanunu'ndaki (5510) maddeden alan bu kampanyanın temel amacı, oyuncuların statüsünü 4B'den 4A'ya çevirerek oyuncuların serbest meslek erbabı olarak değil de bağımlı çalışan, yani 'işçi' olarak tanımlanmasını sağlamaktır. Oyuncuların işçi olarak tanımlanması, setlerdeki maddi çalışma koşulları düşünüldüğünde önem arz etmektedir. Öncelikle oyuncular eğer işçi olarak tanımlanırsa, iş günlerini sekiz saat ve mesaiyle beraber en fazla on bir saat olarak sınırlandırma şansına sahip olacaktır. Buna ek olarak emeklilik, 4A kapsamında daha kolay ve avantajıdır. Çünkü 4B'ye tabi serbest meslek erbabı kendi sosyal güvenlik primlerini yatırmak ve emekli olmak için de daha fazla beklemek zorundadır. Ayrıca, oyuncular 4A kapsamına alınırsa, kendi deyimleriyle 'kelepçe sözleşme'den de kurtulabilecektir ki söz konusu tipte hazırlanan sözleşmelerde yapımcılara istedikleri an herhangi bir gerekçe olmaksızın ve tazminat ödemeksizin sözleşmeyi fesih etme hakkı verilmektedir.

Daha önce de belirtildiği gibi dizi endüstrisine dair tartışmalar daha çok bölüm sürelerine odaklanmaktadır. Ancak Oyuncular Sendikası, tartışmanın çerçevesinin bu şekilde çizilmesinden rahatsızdır. Dizi sürelerinin ne kadar olacağı konusunda bir yaptırımları olamayacağını belirten bir sendika yetkilisi, sorunlarının yapısal ve hukuk temelli olduğunda ısrarcıdır: 
"Çözüm daha kısa dizi çekmekten geçmiyor. Yasanın uygulanması ve oyuncuların işçi olarak sınıflandırılması gerekiyor. Sektöre pansuman değil kemoterapi gerekiyor." (Oyuncular sendikası görevlisi)

Aynı sendika görevlisi, yasal düzenlemeye referansla, oyuncuların statülerini maça 2-0 geriden başlayan bir futbol takımına benzetmiştir. Çünkü mevcut iş̧̧i sendikalarının üyelerini işçi olarak tanımlamak konusunda bir sıkıntısı yoktur. Yapım şirketleri oyuncuların 4B'ye bağı çalışması gerektiğini dile getirse de sendika, oyuncuların işçi olduğunu dile getirmekte ve oyuncuların da ücret karşılığı, başkasının belirlediği zaman ve mekânlarda çalışmak zorunda olduğunu vurgulamaktadır.

Ne var ki medyada endüstriye dair temsillerin genelde parıltılı bir dünyaya işaret etmesi nedeniyle oyuncuların ve ünlü yıldızların işçi olarak sınıflandırılması o kadar kolay olmamaktadır. Sendika görevlileri, 4A kampanyaları nedeniyle kendilerine medya ve yapımcılar tarafından eleștiriler yöneltildiğini ve oyuncuların aldığı ücretlere dair medyadan edinilen bilgilerin (Semercioğlu 2012) önlerine konulduğunu dile getirmektedir:

“Şirketlerin CEO'ları bile iş kanununa göre çalışmakta. Sektöre dair düşünceler insanların aklını maniple ediyor. Insanlar, oyuncuların düzenli bir işi olmadığı gerçeğini unutuyor." (Sendika görevlisi)

Işte bu bağlamda kendilerine "başrol sendikası" denilmesinden şikâyet eden sendika görevlileri, "başrol dayanışmanın" sloganıyla birtakım girişimlerde bulunarak hem hükümetle görüşmeler gerçekleştirmiş hem de sektördeki yapım şirketlerine mektup göndererek oyuncularla şirketler arasındaki yasal ilişkinin yanlış tanımlandığını ve bu yanlışlığın, mevcut yasanın uygulanmasıyla giderilebileceğini vurgulamıştır.

Yapımcılar da oyuncuların bu taleplerine farklı stratejilerle cevap verme yolunu seçmiştir. Söz konusu stratejilerden ilki, işçi olarak tanımlanmaları halinde oyuncuların telif haklarından faydalanmalarının mümkün olmayacağıdır ki Oyuncular Sendikası bu görüşü geçerli bulmamaktadır. Yapımcıların diğer stratejisi ise sektördeki oyuncuların kültür emekçileri olarak emek sürecinde hoşlandıkları görece özerk pozisyonları olmuştur. Yapımcılar, 4A kapsamına alınmaları halinde oyuncuların ofiste 9-5 çalışmaya zorlanacağı argümanıyla oyuncuların karşısına çıkmıştır. Ancak sendikaya göre bu iddia temelsizdir. Çünkü mevcut İş Kanunu'nda sınırlı süre için esnek kontratlar yapılması mümkündür ve bu sayede on üç bölümlük ya da çağıı üzerine kontratlar yapılması söz konusu olabilecektir. Yapımcıların 4A kampanyasına karşı geliştirdiği üçüncü strateji de oyuncuların emek sürecindeki görece özerk konumlarıyla ilgilidir. Yapımcılar, 4A'ya tabi olmaları halinde oyuncuların birden fazla işte çalışamayacağını söylese de sendika, oyuncuların kendi sözleşmelerinin maddelerini ve içeriğini belirleme özgürlügüne vurgu yapmaktadır. 
Yapımcıların söz konusu argümanlarına rağmen 4A kampanyası kısmen de olsa bazı olumlu sonuçlar doğurarak Çalışma ve Sosyal Güvenlik Bakanlığı nezdinde dizi setlerinde çalışmanın statüsü, "az tehlikeli"den "tehlikeli"ye kaydırımıştır. Her ne kadar Oyuncular Sendikası iş yerlerinde hâlâ yeterince denetim yapılmadığından şikâyet etse de sendika çalışanları, kampanyaları sayesinde oldukça karmaşık bir sektörde toplumsal bir hafıza ve hukuki doktrin üretimi anlamında önemli işler yaptıklarını dile getirmekte ve sektörün ileride bunlardan faydalanacağını vurgulamaktadır.

\section{"Senaryo Değil, Gerçek Cinayet": İşçi Sağlığı ve İş Güvenliği Kampanyası}

Gerçekleştiği tarih itibarıyla ironik ve acı bir şekilde 1 Mayıs 2012'de İstanbul Seyrantepe'de dizi sektöründe iz bırakan bir ölüm yaşandı. Arka Sıradakiler dizisine catering hizmeti veren şirketin aracı kontrolden çıkarak sanat asistanı Selin Erdem'in ölümüne neden oldu (Vardar 2015). Selin Erdem'in ölümü, set çalışanlarının ara verdiği sırada yaşandı. Çünkü ara, uygun bir mekân olmadığı için kaldırımda verilmişti. Erdem'in davasının görüldüğü mahkeme, sendikayı müdahil olarak kabul etmedi. Her ne kadar Çalışma ve Sosyal Güvenlik Bakanlığı müfettişleri Selin Erdem'in işverenlerini kusurlu bulsa da bu kişiler mahkemece yargılanmadı ve Anayasa Mahkemesi de işverenlerin ceza soruşturmasına dâhil edilmesine gerek görmedi. Araç sürücüsü taksirle ölüme sebebiyet vermekten ceza alırken, dizinin yönetmeni Hamdi Alkan, Selin Erdem'in ölümünün iş kazasından değil ecelden kaynaklandığını belirterek şunları söyledi:

“30 yıldır bu işin içindeyim ve sektörün bütün sorunlarını biliyorum. Bu işin gerçekleri var. Beğenmeyen bu işi yapmayacak. Ya da oturacağız hep birlikte bu işi yoluna koyacağız. Bu işin realitesi şu anda budur. 1 Mayıs günü evet çalıştık. Ben kendimi bildim bileli çalıştım. Iş̧̧i, emekçi bayramıdır ve çalışarak da kutlanabilir." (Semercioğlu 2012)

Dizi sektöründe ölümler ve iş kazalarının münferit olaylar gibi görülmesi, sektördeki ağır çalışma koşullarını önemsizleştirmektedir. Set ziyaretlerinde göze çarpan en önemli unsurlardan birisi, setlerde yoğun miktarda sigara, kahve ve çay tüketilmesi ve çalışanların düzenli uyku uyumamasıdır. Set çalışanları, servislerde uyuyarak dinlenebilmekte, setlerde yeterince ışık olmadığı için çukura düşebilmekte ya da patlama sahnelerinin çekimlerinde yaralanmalar yaşanmaktadır. Oyuncular Sendikası için çalışan bir iş güvenliği uzmanının da belirttiği gibi her ne kadar dışarıdan şaşalı bir hayat arz etse de "setlerin inşaattan farkı yok"tur. Setler, sabit bir alan değildir ve gece gündüz yeniden kurulan yerlerdir. Ara vermek için her zaman uygun alanlar olmayabileceği gibi insanlar gece-gündüz sokakta, zaman zaman patlayıcı maddelerle çalışmakta ve ağır malzemeler taşımaktadır.

İş̧i Sağliğı ve İş Güvenliği Kampanyası kapsamında yönetmelik çalışması, teknik çalışma ve toplantılar yapılmış ve bütün bu çalışmaların ışığında bir kılavuz ortaya çıkmıştır. Söz konusu Setlerde Işçi Sağlığı ve Güvenliği Rehberỉnin en önemli 
işlevlerinden birisi, teknolojinin sürekli değiştiği bir ortamda, setlerdeki tehlikelere ve gerekli önlemlerin nasıl ve kimler tarafından alınacağına işaret ediyor olmasıdır. Sekiz farklı çalışan grubunun (oyuncular, yönetmen ve reji ekibi, ışık ekibi, sanat ekibi, görüntü yönetmeni/kamera asistanı/dolly operatörü, özel efekt ekibi, set ekibi, post prodüksiyon) belirlendiği rehberde iş kazalarının önlenmesi için set çalışanlarının kullanabileceği bir kontrol listesi ve iş kazası olması durumunda dikkat edilecek noktalara da yer verilmiştir.

\begin{tabular}{|c|c|c|c|c|c|c|c|c|}
\hline 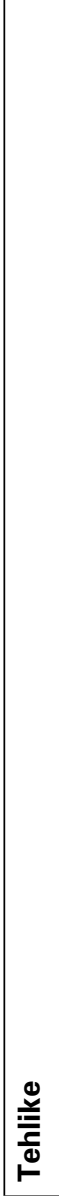 & 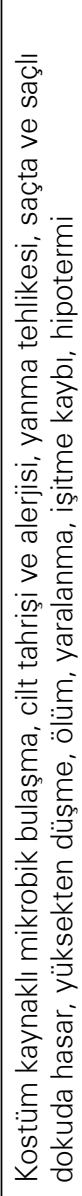 & 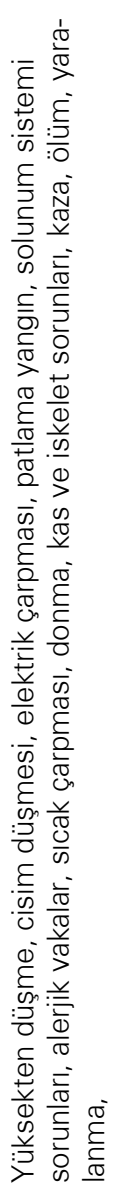 & 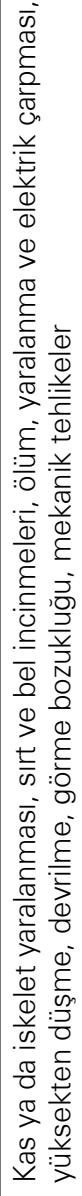 & 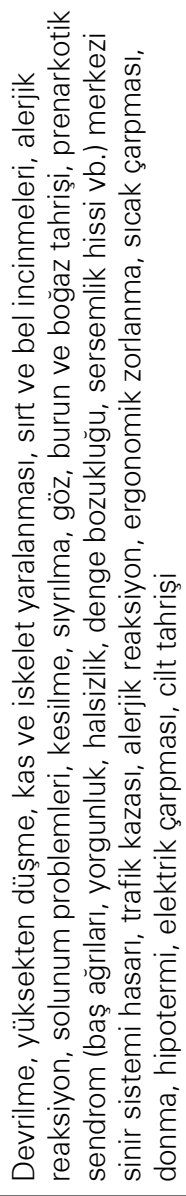 & 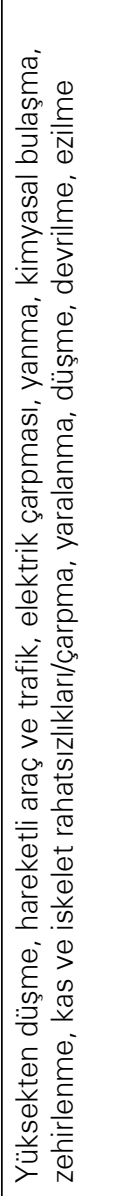 & 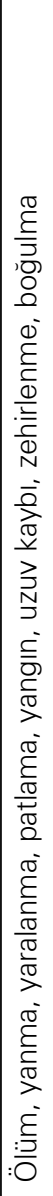 & 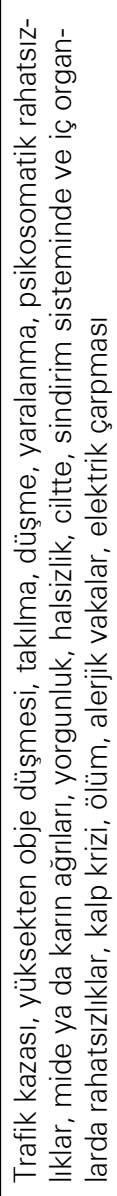 & 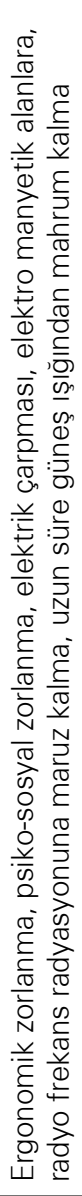 \\
\hline 흠 & 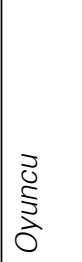 & 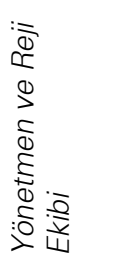 & $\begin{array}{l}\frac{a}{w} \\
w \\
\frac{v}{w}\end{array}$ & 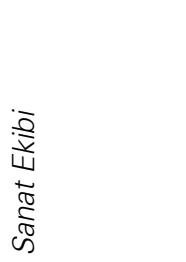 & 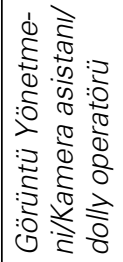 & 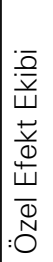 & $\begin{array}{l}\frac{a}{0} \\
\frac{a}{0} \\
\text { d } \\
\text { c) }\end{array}$ & $\begin{array}{l}\delta \\
\frac{1}{2} \\
0 \\
\frac{1}{2} \\
0 \\
0 \\
0 \\
\frac{1}{2} \\
0 \\
0\end{array}$ \\
\hline
\end{tabular}

Tablo, Setlerde İşçi Sağlığı ve Güvenliği Rehberi'nden kısaltılarak hazırlanmıştır. 
Yukarıdaki tablodan da anlaşılacağı gibi ekranlarda izlediğimiz renkli görüntülerin ardında, uzun çalışma saatlerinden ve setlerin karmaşık ve sabit olmayan yapılarından kaynaklanan tehlikeler, kaza riskleri ve önemli boyutta bedensel bir külfet yatmaktadır. Tablo ayrıca, daha önce de vurgulandığı üzere dizi sektöründe sadece ekonomik göstergeler ve istihdam boyutuyla anlaşılamayacak derecede karmaşık ve fiziksel/bedensel boyutlarda güvencesizlikler söz konusudur. Yine tablodan hareketle, güvencesizliğin sadece çizgi altı dizi çalışanları için değil, görece iyi koşullarda ve iyi ücretlerde istihdam edilen çizgi üstü emekçiler için de geçerli olduğunu söylemek mümkün olacaktır.

\section{Sonuç}

Yaratıcı emek ve yaratıcı endüstriler üzerine yapılan çalışmalarda araştırmacıların altını ısrarla çizdiği iki anahtar kelime olduğunu söyleyebiliriz: tutku ve güvencesizlik. Tutku söz konusu olduğunda, Türk dizi sektörünün bir istisna olmadığı, yapılan görüşmelerde de ortaya çıkmıştır. Çizgi altı ve üstünde yer alan dizi emekçileri, zor koşullara rağmen işlerini sevdikleri için -tabii ödemek durumunda oldukları borçları da göz ardı etmeden- sektörde kaldıklarını dile getirmişlerdir. Bununla birlikte, işi aşk ve tutkuyla yapmak gerektiğine dair söylemin, sektörün önde gelen yapımcıları tarafından yeniden üretilen ideolojik bir altyapısı olduğunu vurgulamak gerekmektedir. Örneğin Osman Yağmurdereli, "çaycının haftalığı bile 250 YTL'den başlıyor" diyerek sektöre dair pırıltılı bir resim çizmektedir (Kuburlu 2006).

Tutkunun yanı sıra dizi sektörünü tanımlayan ikinci anahtar kelime de güvencesizliktir. Bu makalenin yazıldığı tarih itibarıla Paramparça gibi önde gelen bir yapım bile görece iyi reyting almasına rağmen yıldızlarının setteki anlaşmazlıkları nedeniyle geleceğe dair belirsizlik yaşayabilmektedir. Tabii sektördeki güvencesizliğin birinci nedeninin, yeni reyting sistemi ve buna bağlı uzun çalışma saatleri olduğu unutulmamalıdır. Hollywood'a kıyasla Türkiye dizi sektörü, dijitalleşmeyle başa çıkmak ve "analog dolarları dijital penilere" çevirmek gibi sorunlardan ziyade (Banks 2010: 22) yeni reyting sisteminde ayakta kalmaya çalışmaktadır. Bu anlamda "tahmin edilemez olanı tahmin etmenin" (Gitlin 1983/1994) hâlihazırda zaten zor olduğu bir sektörde, yeni reyting sistemi işleri daha da karmaşıklaştırmaktadır. Üstelik yeni sistem, güvencesizliği çizgi üstü dizi çalışanları açısından da daha çok yaşanan bir deneyim haline getirmiştir.

Güvencesizliğin farklı katmanları ve biçimleri olduğuna dair argümanlar farklı araştırmalarda dile getirilse de (de Peuter 2011) Türk dizi sektöründeki güvencesizlik, yalnızca ekonomik ve istihdam boyutuyla anlaşılamaz ve dolayısıyla da bedensel ve fiziksel boyutlarıyla mevcut literatürden ayrılmaktadır. Ana akım medyadaki pırıltılı görüntülerin aksine, reyting sisteminin dizilerde çalışanların bedenleri üzerindeki etkisi, iş kazaları ve ölümler aracılığıyla görünür hale gelmektedir. Ne var ki, mevcut araştırma güvencesizliğin fiziksel/bedensel boyutunun yanında bir başka argümanla da literatüre katkı sağlamaktadır. Yaratıcı 
endüstrilerde istihdam edilen iş gücüne dair araştırmalarda çalışanlar, öz-sömürüyü (self-exploitation) gönüllü olarak üstlenen, işkolik, uzun saatler çalışmaktan ve işle eğlencenin iç içe geçmesinden hoşlanan özneler olarak kurgulanmaktadır (Kücklich 2009; McRobbie 2001). Buna ek olarak yeni yaratıcı ekonominin kültür emekçilerinin, genel olarak sendikal örgütlenmeye karşı olduğu dile getirilmekte ve buna sebep olarak sendikaların işlevsizliği ya da bireysel iş kültürüne daha yatkın olmak gibi nedenler dile getirilmektedir (Banks 2010; Sennett 1998).

Ancak makalede de vurgulandığı üzere dizi sektöründe çalışanlar, şikayet etmekle yetinmeyip güvencesizlikle mücadele etmeyi seçmiş ve bunun için hem Oyuncular Sendikası'nı hem de Sinema TV Sendikası'nı kurmuşlardır. Sinema TV Sendikası 2015 Haziran'ında kurulduğu için bu araştırmaya dâhil edilmemiştir. Ancak Oyuncular Sendikası, yürüttüğü kampanyalarla oyuncuların dizi sektöründeki çalışma koşullarının iyileştirilmesi ve sözleşmelerinin işçi statüsünde yapılması için mücadele etmektedir. Bu oluşum, devletle girdiği ilişki, oyuncuların işçi olarak tanımlanması talebi ve meslek tanımlarının yapılması yönündeki çalışmalarıyla da kültür endüstrilerinde diğer örgütlenmelerden farklııı arz etmektedir. Zira özellikle Kuzey Amerika gibi coğrafyalarda sendikalar yerine kooperatif gibi daha alternatif oluşumlar ön plana çıkarken Türkiye dizi sektörü, içinde bulunduğu tarihsel şartlarda sendikalaşmayı tercih etmiştir.

\section{Kaynakça}

Alphan, M. (7 Aralık 2011). Türkiye'nin Yumuşak Gücü: Dizileri. Hürriyet. Erişim 5 Mayıs 2016, http://www.hurriyet.com.tr/turkiye-nin-yumusak-gucudizileri-19414165

Al Jazeera Turk. (21 Şubat 2014). Türk Dizilerin Rekoru. Erişim 5 Mayıs 2016, http://www.aljazeera.com.tr/al-jazeera-ozel/turk-dizilerinin-rekoru

Banks, M. (2010). Autonomy Guaranteed? Cultural Work and the 'Art-Commerce Relation'. Journal for Cultural Research, 14 (3), 251-270.

Banks, M. (2010). The Picket Line Online: Creative Labor, Digital Activism, and the 2007-2008 Writers Guild of America Strike. Popular Communication: The International Journal of Media and Culture, 8 (1), 20-33.

Başaran, E. (25 Aralık 2014). 5 yıl sonra hepimiz bu sektörden çekilmek zorunda kalabiliriz. Radikal. Erişim 8 Mayıs 2016, http://www.radikal.com.tr/yazarlar/ezgibasaran/5-yil-sonra-hepimiz-bu-sektorden-cekilmek-zorunda-kalabiliriz-1258384/

Binark, M. ve Bayraktutan-Sütçü, G. (2008). Kültür Endüstrisi Olarak Dijital Oyun. İstanbul: Kalkedon.

Blair, H. (2001). 'You're only as good as Your Last Job': The Labour Process and Labour Market in the British Film Industry. Work, Employment, Society, 15(1), 149-169. 
Cohen, N. (2015). From Pink Slips to Pink Slime: Transforming Media Labor in a Digital Age. The Communication Review, 18(2), 98-122

Curtin, M. (2008). Spatial Dynamics of Film and Television. H. Anheier ve Y.R. Isar, (Ed.). The Cultural Economy içinde (215-226). Londra: SAGE

Çaylı, E. (2012). Genel Ahlak, Genel Halk ve Cinsiyetlendirilmis Diziler Ülkesinden Kolajlar. Kampfplatz, 1(1), 201-211.

de Peuter, G. (2011). Creative Economy and Labor Precarity: A Contested Convergence. Journal of Communication Inquiry, 35 (4), 417-425.

de Peuter, G. ve Cohen, N. (2015). Emerging Labour Politics in Creative Industries. K. Oakley ve J. O'Connor, (Ed.), The Routledge Companion to the Cultural Industries içinde (305-318). Londra: Routledge.

Dünya'nın En Renkli Ekranı: Türkiye'de Dizi Sektörü (2014). Erişim 05 Mayıs 2016, http://www2.deloitte.com/content/dam/Deloitte/tr/Documents/technologymedia-telecommunications/tr-media-tv-report.pdf

Dyer-Witheford, N. ve de Peuter, G. (2009). Games of Empire: Global Capitalism and Video Games. Minneapolis: University of Minnesota Press.

Ertan, M. (2013). Türkiye'de Popüler Dizilerden Adalet Manzaraları. Kampfplatz, 1(3), 263-277.

Florida, R. (2005). Cities and The Creative Class. New York, London: Routledge.

Fuchs, C. (2013). Digital prosumption labour on social media in the context of the capitalist regime of time. Time and Society, doi: 10.1177/0961463X13502117

Fuchs, C. (2014). Digital Labor and Karl Marx. New York: Routledge.

Gitlin, T. (1983/1994). Inside Prime Time. Londra: Routledge.

Hesmondhalgh, D. ve Baker, S. (2011). Creative Labour: Media Work in Three Cultural Industries. New York \& London: Routledge.

Turkey World's Second Highest TV Series Exporter After US. (26 Ekim 2014). Hürriyet Daily News. Erişim 06 Mayıs 2016, http://www.hurriyetdailynews.com/ turkey-worlds-second-highest-tv-series-exporter-after us.aspx?pagelD=238\&nID $=73478 \&$ NewsCatID $=345$

Kerr, A. (2006). The Business and Culture of Digital Games: Gamework/Gameplay. London: SAGE.

Konuşlu, F. (2012). Production and Labour Process of the Contemporary Turkish Private Television Series. Ankara: ODTU Sosyal Bilimler Enstitüsü.

Konuşlu, F. (2013). Emek Süreci Analizinden Sınıf Tartışmasına Bir Yol Denemesi: Türkiye Özel Televizyon Dizilerinin Üretim ve Emek Sürecinde Sınıfsal Illişkiler. Praksis Dört Aylık Sosyal Bilimler Dergisi, 2(32), 165-189. 
Kraidy, M. ve Al-Ghazzi, O. (2013). Neo-Ottoman Cool: Turkish Popular Culture in the Arab Public Sphere. Popular Communication: The International Journal of Media and Culture, 11, 17-29.

Kuburlu, C. (23 Ekim 2006). TV'de haftada 16 milyon YTL'lik dizi izliyoruz. Hürriyet. Erişim 06 Mayıs 2016, http://www.hurriyet.com.tr/tv-de-haftada-16-milyon-ytl-likdizi-izliyoruz-5303491

Kücklich, J. (2009). Virtual Worlds and Their Discontents Precarious Sovereignty, Governmentality, and the Ideology of Play. Games and Culture, 4(4), 340-352.

Mayer, V. , Banks, M. ve Caldwell, J. T. (Ed.). (2009). Production Studies: Cultural Studies of Media Industries. New York: Routledge.

McRobbie, A. (29 Ağustos 2001). Everyone is creative: artists as new economy pioneers? Erişim 06 Mayıs 2016, https://www.opendemocracy.net/node/652

Nurgül Yeşilçay Yatıım Yapıyor. (19 Mart 2015). Milliyet. Erişim 06 Mayıs 2016, http://www.milliyet.com.tr/nurgul-yesilcay-yatirim-yapiyor--magazin-2031117/

Soap Opera Tourism. (Ocak 2010). Erişim 06 Mayıs 2016, http://monocle.com/ film/culture/soap-opera-tourism/

Engin Günaydın Oyunculuğu Bıraktı mı? (14 Ekim 2015). Radikal. Erişim 06 Mayıs 2016,http://www.radikal.com.tr/hayat/engin-gunaydin-oyunculugu-biraktimi-1451290

Randle, K. (2011). The Organization of Film and Television Production. M. Deuze (Ed.), Managing Media Work içinde (145-154). Londra: Sage.

Scholz, T. (Ed.). (2012). Digital Labor: The Internet as Playground and Factory. New York: Routledge.

Semercioğlu, C. (07 Mayıs 2012). Beğenmeyen bu işi yapmasın. Hürriyet. Erişim 06 Mayıs 2016, http://www.hurriyet.com.tr/begenmeyen-bu-isi-yapmasin-20505884

Sennett, R. (1998). The corrosion of character: the personal consequences of work in the new capitalism. New York, London: W.W. Norton.

Tanriöver, H. (2010). Türkiye'de Film Endüstrisinin Konumu ve Hedefleri. Istanbul: ITO.

Terranova, T. (2000). Free Labor: Producing Culture for the Digital Economy. Social Text, 18(2), 33-58.

Tokumitsu, M. (2015). Do What You Love and Other Lies About Success and Happiness. New York: Regan Arts.

Tüzün, S. ve Şen, A. (2014). The Past as a Spectacle: The Magnificent Century. R. G. Öztürk, (Ed.), Handbook of Research on the Impact of Culture and Society on the Entertainment Industry içinde (182-202). Hershey, PA: IGI Global. 
Tüzün-Ateşalp, S. ve Taşdemir, B. (2014). Ürün Yerleştirme ve Editoryal İçerik ile Illgili Artan Kaygılar: Türkiye'de Televizyon Draması Sektörü Örneği. Galatasaray iletişim Dergisi, 21, 51-78.

Ursell, G. (2000). Television Production: Issues of Exploitation, Commodification and Subjectivity in UK Television Labour Markets. Media Culture and Society, 22, 805-825.

Vardar, N. (28 Ocak 2015). Selin Erdem'in Öldüğü "Tehlikeli Set" AlHM'de. Erişim 06 Mayıs 2016, http://bianet.org/bianet/toplum/161874-selin-erdem-inoldugu-tehlikeli-set-aihm-de

Yücesan-Özdemir, G. (2014). İnatçı Köstebek: Çağrı Merkezlerinde Gençlik, Sınıf ve Direniş. Ankara: Yordam Yayınları.

Wittel, A. (2001). Toward a Network Sociality. Theory Culture and Society, 18(6), 51-76. 